العدد الثاني والأربعون

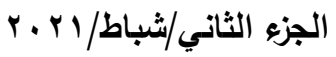

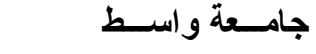

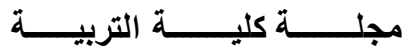

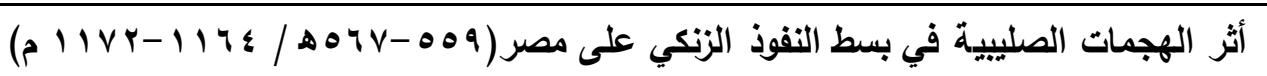

م.د. جاسم محمد عباس

كلية الإمام الكاظم (ع) للعلوم الإسلامية الجامعة

\title{
أقسام واسط
}

jassimmuhammed58@gmail.com

ملخص البحث : - مالم:

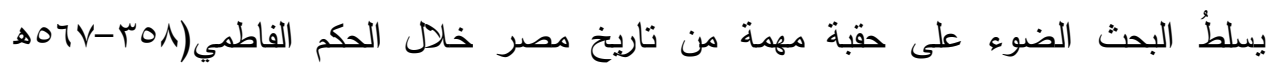

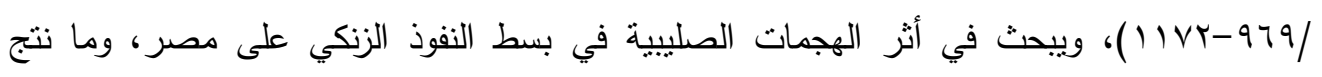
عنها من احداث سياسية مهمة، وكبيرة في تاريخ هذه البلاد، الامر الذي ترثب عليه تغير واضح في خارطتها السياسية .

ففي الوقت الذي كانت القوات الصليبية نتحين الفرص للشن الهجمات على مصر كان الملك نور الدين زنكي يراقب نلك الهجمات عن كثب، فباشر بإرسال حملاته العسكرية إليها لتأمين حدودها

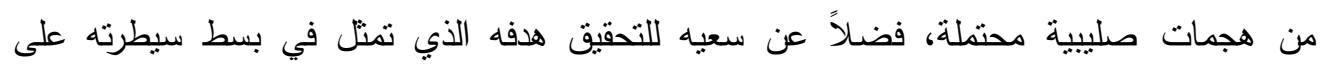

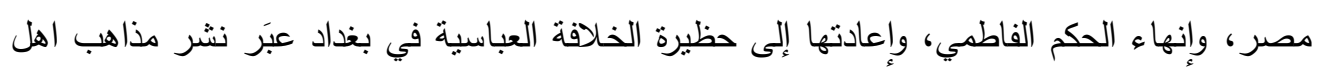
السنة والجماعة فيها، وأناط مسؤولية تتفيذ هذه المهمة الى قائد حملاته العسكرية أسد الدين شيركوه وابن أخيه صلاح الدين الأيوبي، وقد تحقق له ذلك، اذ نجح هؤلاء القادة في بسط النفوذ الزنكي على هلى

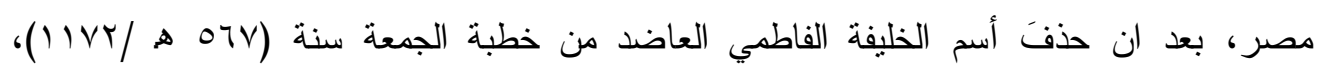
والخطبة للخليفة العباسي في بغداد بدلاًا عنه.

وطبقاً لأهمية تلك الأحداث السياسية وقع اختبارنا لمشروع البحث الذي جاء تحت عنوان (أثر بغان

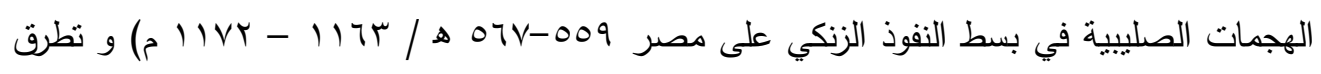
الى الحديث عن الحملات العسكرية الثلاث التي إرسلها الملك نور الدين زنكي إلى مصر لحمايتها من الهجمات الصليبية، فكان لها أبرز الاثر في بسط نفوذه على هذه البلاد.

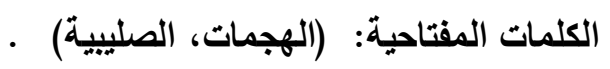



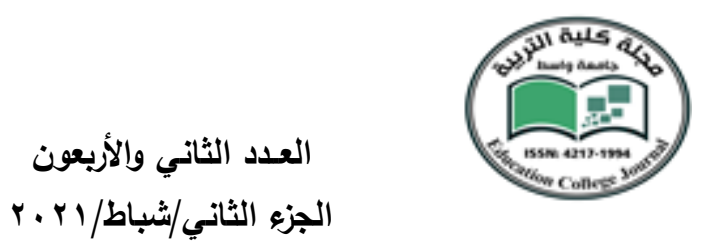

The Impact of the Crusader Attacks on Extending Zanki Influence over Egypt (559-567 AH / 1164-1172 AD))((

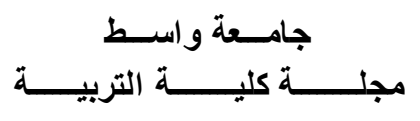

\author{
Dr. Jasim Mohammed Abbas \\ Imam Al-Kadhim (peace be upon him) \\ College of Islamic Sciences University \\ Wasit departments \\ jassimmuhammed58@gmail.com
}

\begin{abstract}
The research sheds light on an important period in the history of Egypt during the Fatimid rule (358-567 AH / 969-1172) and examines the impact of the Crusader attacks on the extension of Zanki influence over Egypt, and the significant political events that resulted from them in the history of this country. It has a clear change in its political map.

In time; The Crusader forces were waiting for opportunities to launch attacks on Egypt, King Noureddine Zangi watched those attacks closely, so he proceeded to send his military campaigns to them to secure their borders from possible crusader attacks, as well as his pursuit of his goal that represented his control over Egypt, ending the Fatimid rule, and returning it to the fold of the Abbasid Caliphate in Baghdad through the publication of the doctrines of the Sunnis and the Jamaa, and the responsibility for implementing this was assigned to the leader of his military campaigns, Asad al-Din Shirkuh and his nephew Salah al-Din al-Ayyubi, and this was achieved for him. These leaders succeeded in extending the influence of the Zangid over Egypt, after the name of the Fatimid Caliph Al-Aded was removed from the Friday sermon in the year $567 \mathrm{AH} / 1172$ and the sermon of the Abbasid caliph in Baghdad instead.

According to the significance of these political events, we chose the research project that came under the title (The Impact of the Crusader Attacks on Extending the Zangid Influence on Egypt 559-567 AH / 1163$1172 \mathrm{AD})$ and touched upon the discussion of the three military campaigns; Which was sent by King Nur al-Din Zangi to Egypt - to secure it from the Crusader attacks - and it had the most prominent effect on extending the Zangid influence over it.

Key Words: (Attacks, Crusades)
\end{abstract}


العدد الثاني والأربعون

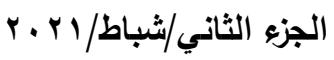

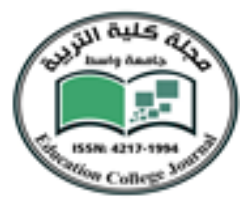

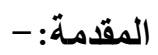

الحمد لله ربّ العالمين، و الصلاة على محمد وآله الطاهرين، وصحبه المنتجبين ، وبعد ...

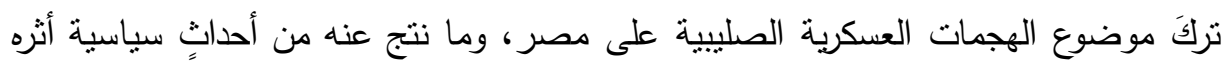

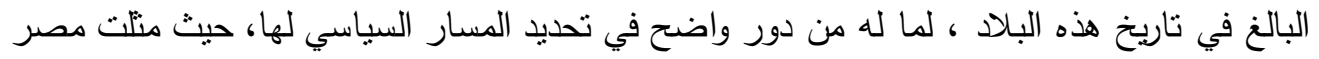

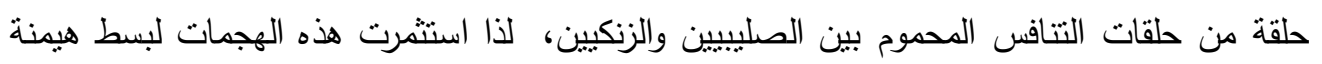

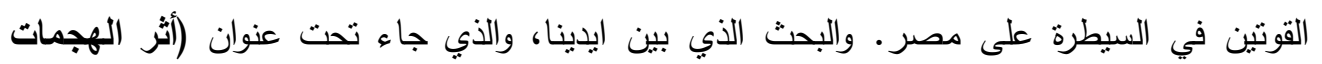

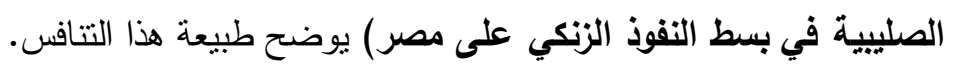

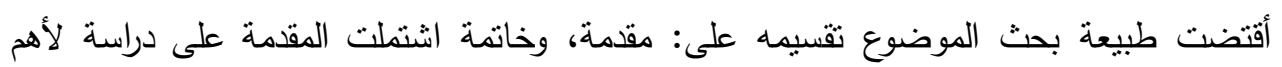

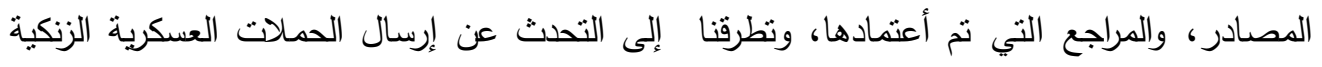
الثلاث الى مصر، وأثزها في بسط النفوذ الزنكي عليها، وانتهى البحث اخيراً بخاتمة ثبتت أهم النتائج الني توصلنا اليها. أعتمد البحث على مجموعة من المصادر والمراجع، كان في مقدمتها كتاب(الكامل في التاريخ)

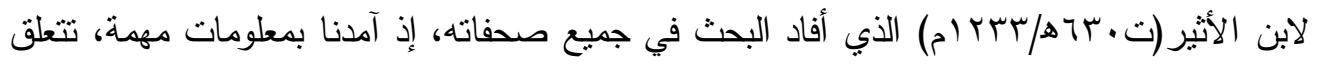

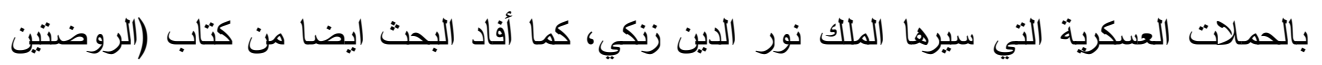

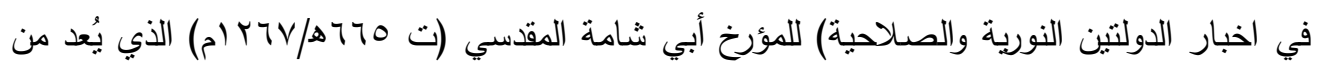

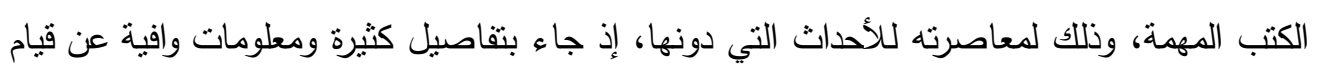

القادة الزنكيين، بالقضاء على الخلافة الفاطمية في مصر . فضلا عن ذلك، أفاد البحث ايضاً من مراجع أخرى، كان من أبرزها كتاب (قيام الدولة الأيوبية

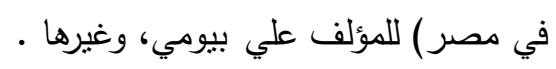

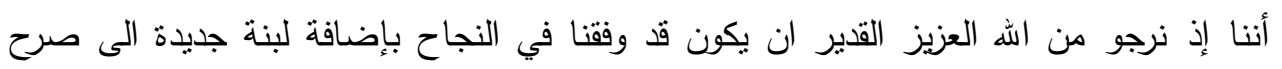

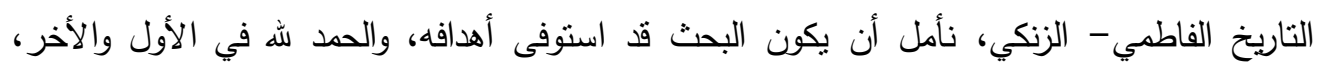
وعليه وحده قصد السبيل.

- حملات الملك نورالاين زنكي العسكرية على مصر:

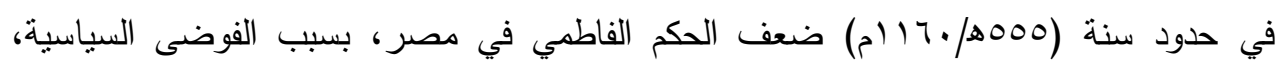
والتتافس المحموم على منصب الوزارة، وكانت تلك الظروف بمثابة الفرصة الذهبية للتخل الصليبيين

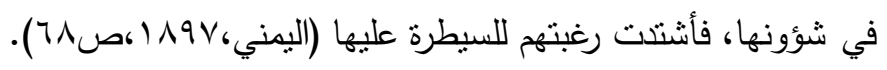


العدد الثاني والأربعون

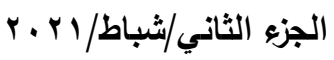

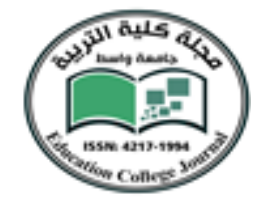

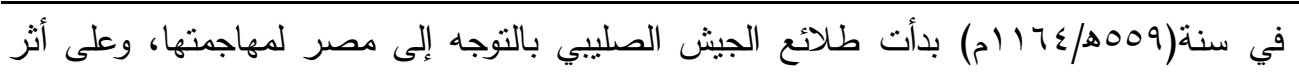

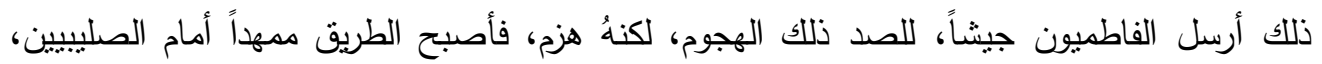

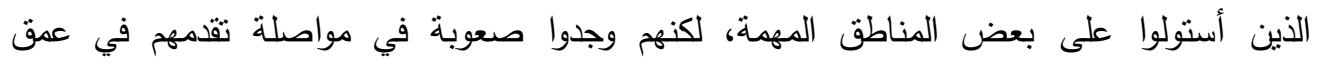

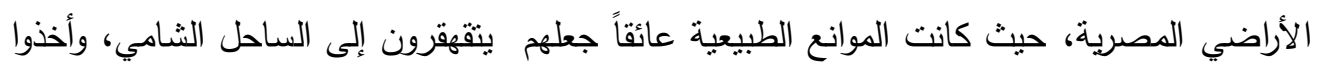

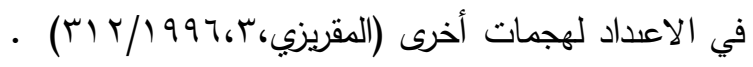

اولاً : الحملة العسكرية الاولى :-

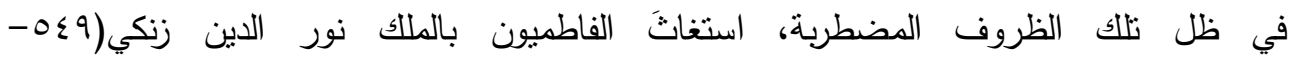

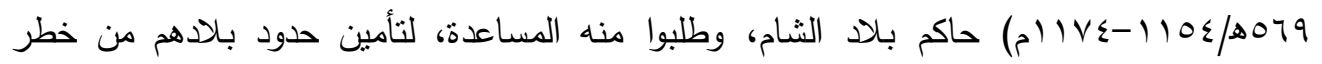

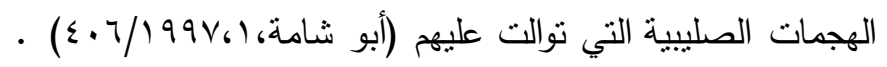

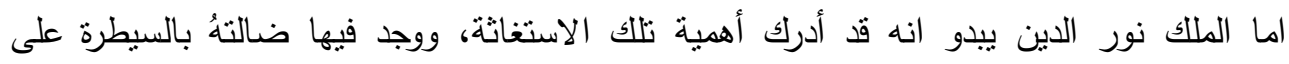

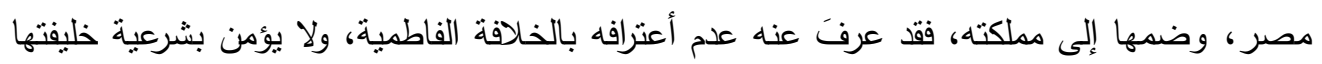

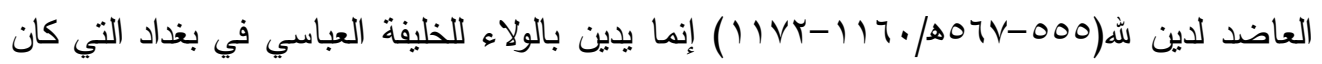

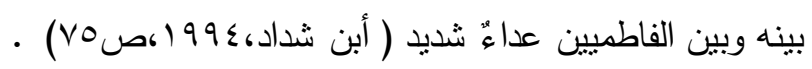

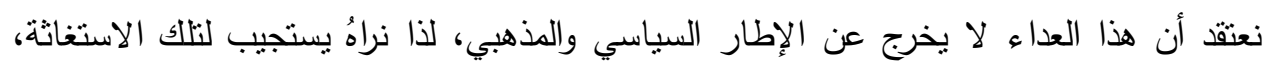

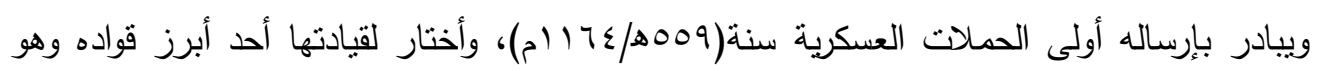

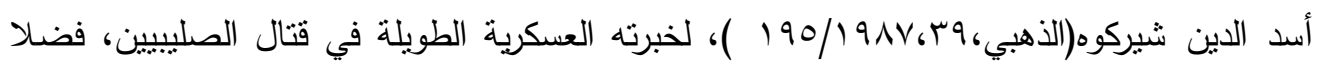

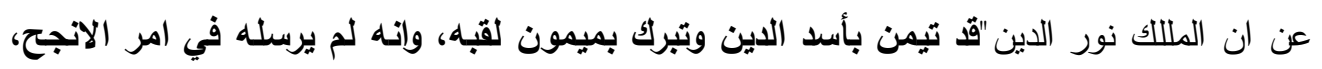

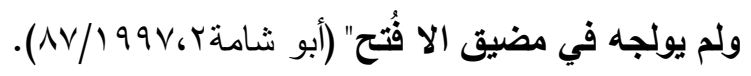

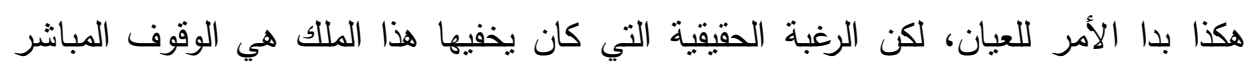

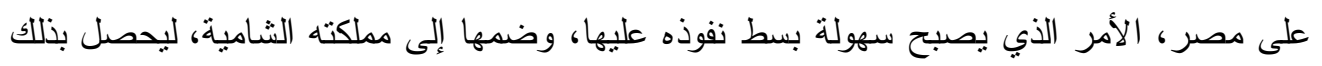

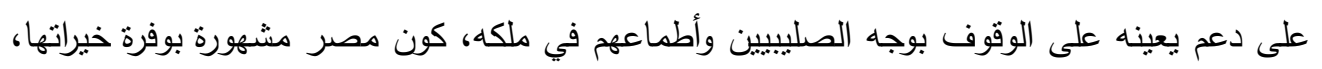

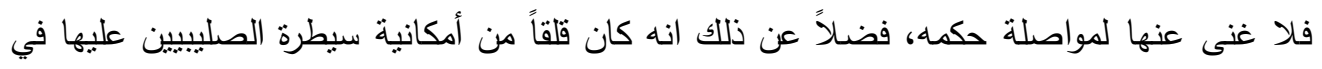

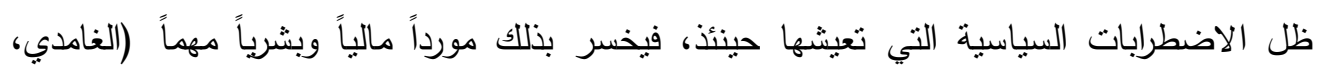

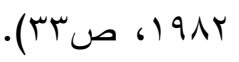

نجحَ القائد أسد الدين شيركوه في الوصول إلى القاهرة، و كان بصحبته ابن أخيه صلاح الدين

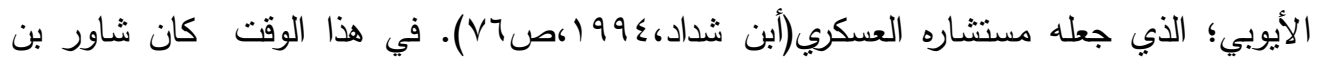


العدد الثاني والأربعون

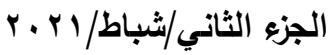

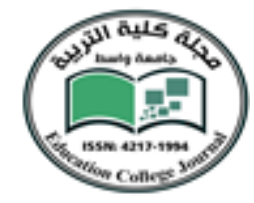

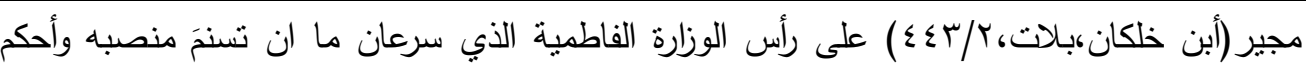
قبضته عليه، حتى تمرد على الخليفة العاضد، وأرسل الى القائد شيركوه - الذي كان معسكراً على أسوار مدينة القاهرة - يطلب منه مغادرة مصر والعودة الى بلاد الثام، إلا ان شيركوه رفض طلبه،

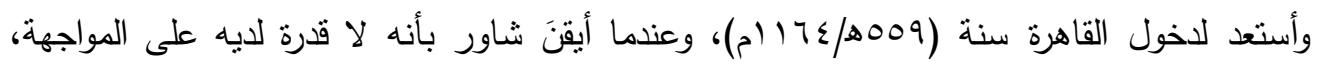
أرسلَ إلى الصليبيين يستغيث بهم، وقد أستجابوا إلى طلبه آملين بذلك بسط سيطرتهم على مصر،

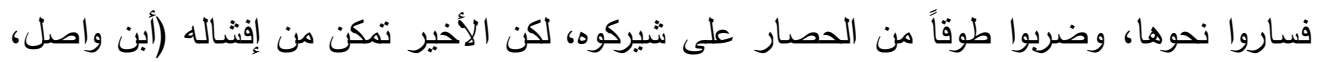

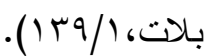

يبدو ان الصليبيين قد تقاجئوا بصمود شيركوه وجنوده، فطلبوا الصلح، فاستجاب لطلبهم، ولعل استجابته لهم كونه لم يكن قادراً أيضاً على مواصلة القتال نظراً ، لمقتل عدد من افراد جيشه، فضـالًا

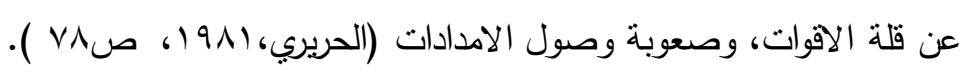

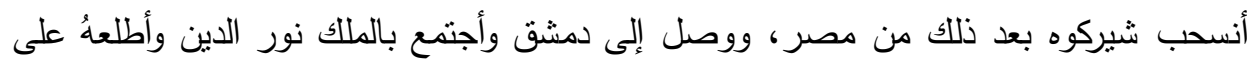
نتائج الحملة، ومنها ضعف التي كانت تعانيه مصر، الأمر الذي يسهل السيطرة عليها، اما الصليبيون فأنسحبوا من مصر ، وعادوا إلى نكناتهم العسكرية بعد ان بذل لهم الوزير شاور الأموال

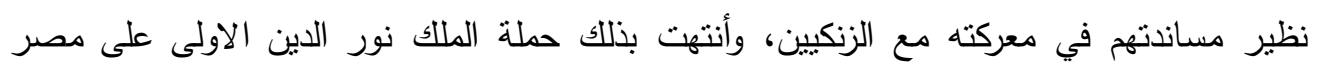

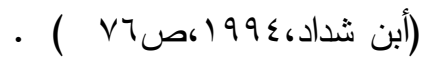

ثانياً: الحملة العسكرية الثانية:بعد ان أنتهت الحملة الزنكية الاولى على مصر ، كان الملك نور الدين يفكر ملياً بضرورة فتحها وبسط سيطرته عليها، ومما لاشك فيه ان تفكيره في ملكها أصبح أكثر وضوحاً بعد تلك بلك

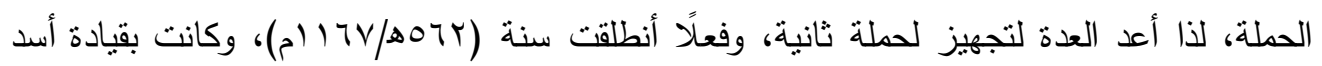
الدين شيركوه ايضاً الذي اصطحب معه ابن اخيه صلاح الدين (ابن الوردي،Y، 1997/ / Ir). واقعاً ان الملك نور الدين - بوصفه رجل سياسي وعسكري محنك- كان على ثقةٍ تامة بسهولة السيطرة على مصر ، وبسط نفوذه عليها، لما كانت نشهذهُ من تدهور وأضطرابات سياسية، فخليفتها ضعيف لا يملك من الامر شيئاً، ووزراؤه انتهازيون كانوا على أستعداد تام للتضحية بمصلحة بلدهم مقابل تحقيق مصالحهم الثخصية، وبذلك حرص الملك نور الدين على الأستحواذ عليها، وضمها إلى

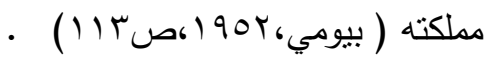


العدد الثاني والأربعون

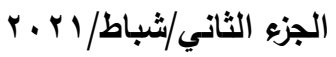
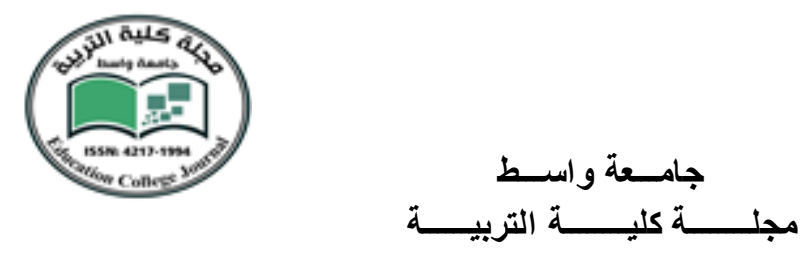

لق ذكر بعض المؤرخين ان سبب توجه حملة الملك نور الدين الثانية صوب مصر كان لحمايتها من هجوم صليبي مرثقب ، سيما بعد التتازلات المقدمة من الوزير المصري شاور للصليبين

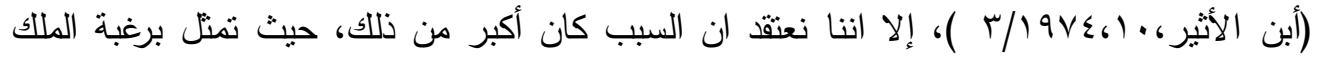
نور الدين في إنهاء الحكم الفاطمي، والقضاء على مذهبه الإسماعيلي، والدليل الذي استتدنا اليه في بي الأدلاء بهذا الرأي هو لليل استتتاجي استتتناهُ عبرَ إستقراء نصوص المصاءر المعاصرة التي أدلت بشيء من نلك في صورة لا تقبل الشك، فقد بالغَ في تحامله وتشدده على الفاطميين، حيث صرف الناس عن مذهبهج، ومنع من انتشاره في بلاد الشام، لا سيما في مدينة حلب التي عرف أهلها

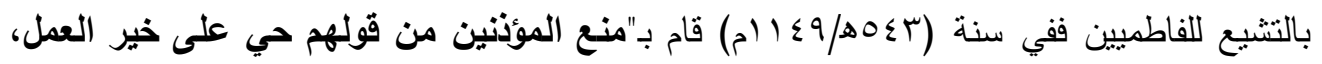
وجلس تحت المنارة ومعه الققهاء، وقال لهم: من لم يؤذن الآذان المشرع فألقوه من المنارة على ملى

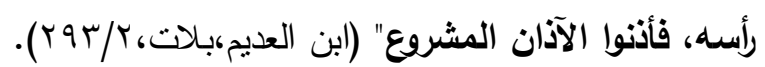

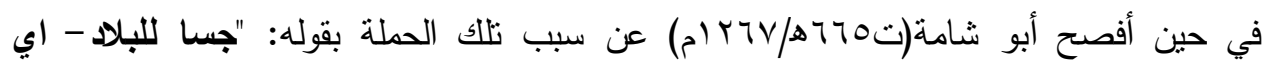

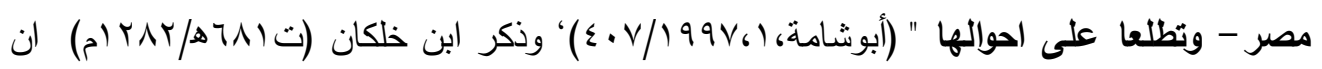
الهدف الذي كان من وراء الحملة النورية الثانية على مصر ان الملك نور الدين: "اراد استعلام احوال مصر، فاته كان يبلغه انها ضعيفة من جهة الجند، واحوالها في غاية الاختلال، فقصد الكثف عن

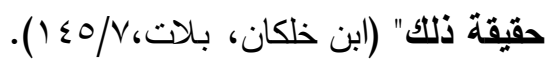

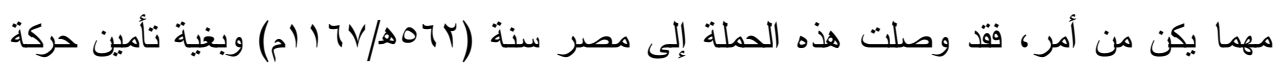

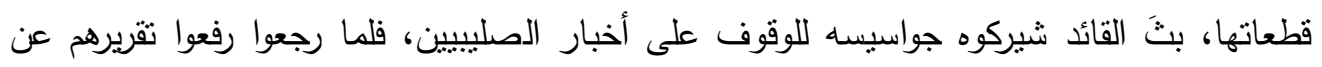

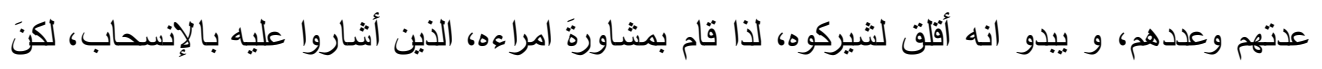

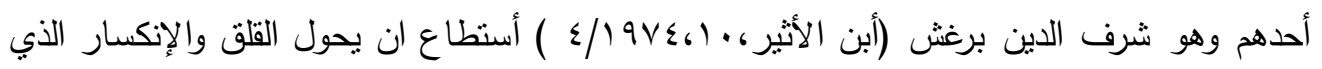
دبَ بين صفوف العسكر إلى ثبات وقوة، فحمسَ المقاتلين على القتال فتحركوا صوب العدو ( أبوشامة $.(1) / 199 V_{6} T_{6}$

ما ان وصلت أنباء هذا التحرك إلى الصليبين، حتى بادروا بالإنسحاب، من مصر ، دون أي أثنتاك عسكري (ابن واصل، بلات، / • 1 1) في حين أمر شيركوه جيشه بالعودة إلى ثكانته ببلاد الشام، وقد

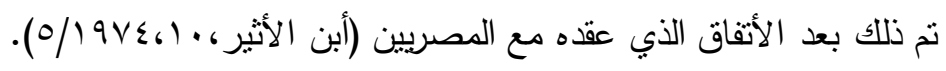


العدد الثاني والأربعون

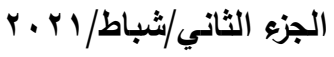

\section{جامسعة واسـط كلئ}

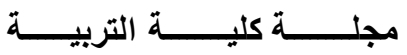

ثالثاً: الحملة العسكرية الثالثة: - -

يبدو ان الصليبيين قد عقدوا العزم على مهاجمة مصر من جديد، للإستيلاء عليها ، وشجعهم

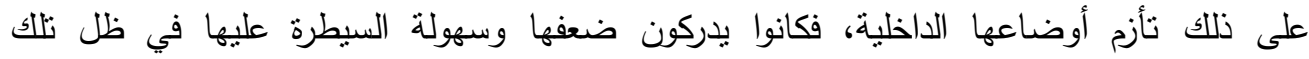

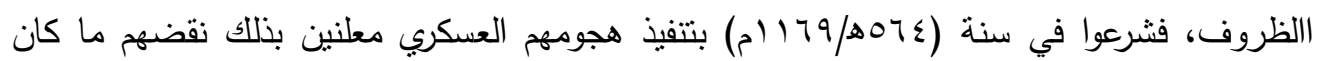

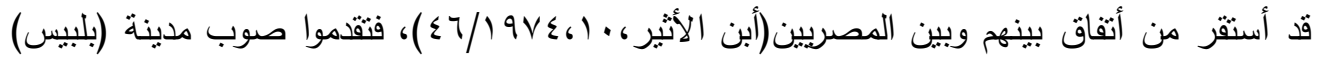

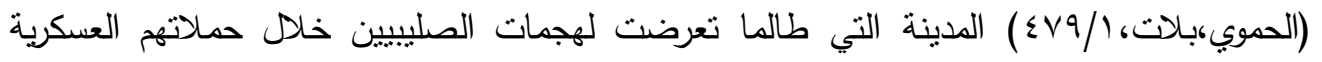

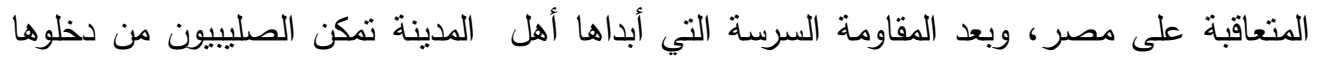

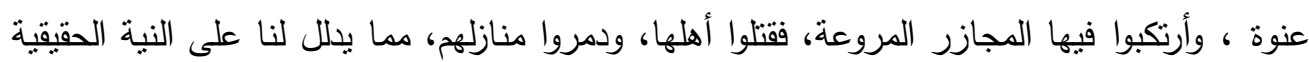

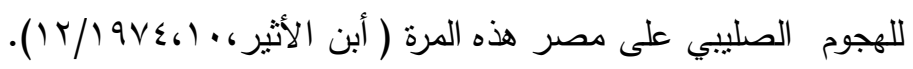
وبعد سقوط بلبيس بإيديهم واصل الصليبيون زحفهم، فوصلوا القاهرة، لكنهم فشلوا في السيطرة

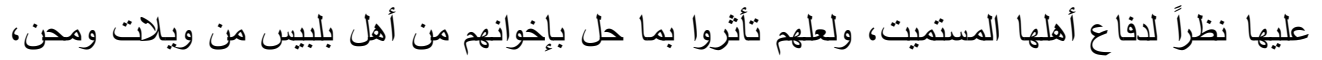

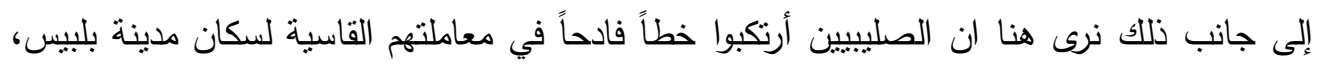

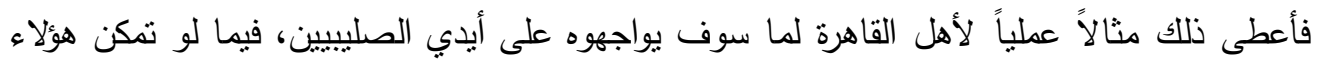

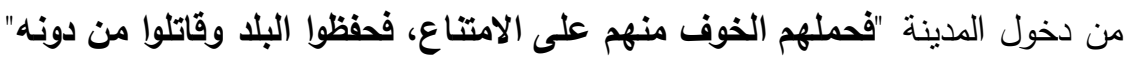

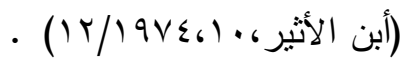

يبدو ان الملك نور الدين زنكي كان يدرك حجم المخاطر المترتبة على تحقيق هدفه في حال سيطرة

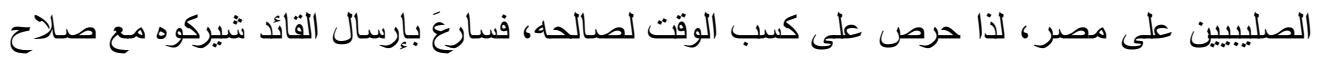

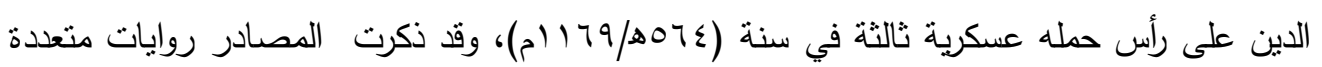

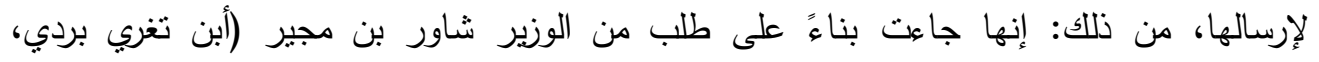

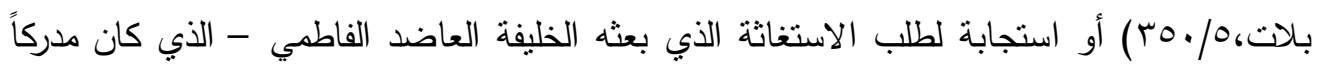

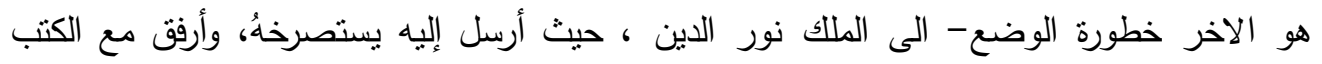

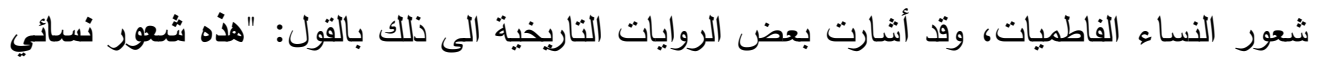

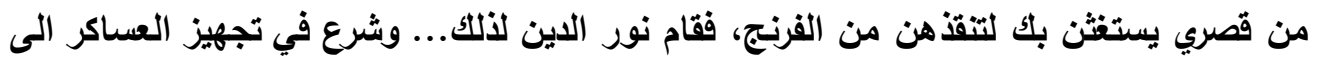

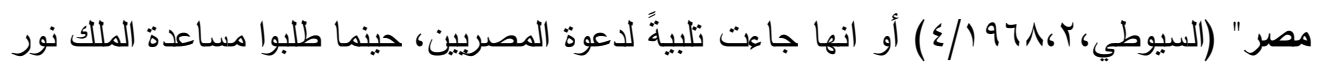

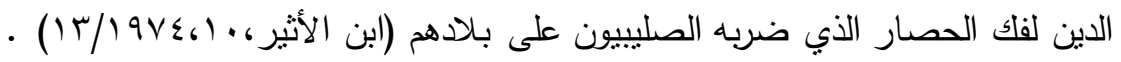

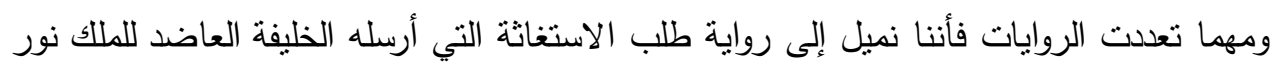

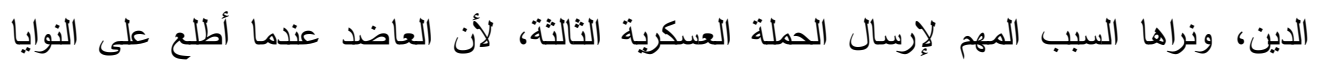


العدد الثاني والأربعون

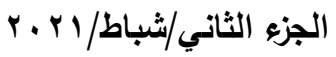

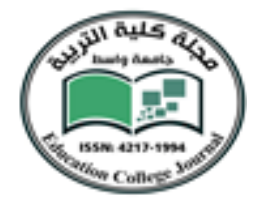

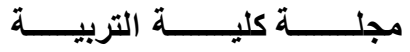

الحقيقية للصليبين، بعثَ الى الملك نور الدين يستصرخه، فنحنُ لا نستبعد استغاتة المسلمين - على تتوع مذاهبهم - ببعضهم ضد عدوهم الواحد، ويضعوا خلافهم السياسي جانباً، ويتوحدوا في مواجهة

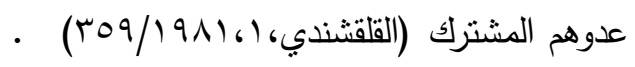

لما وصلَ خبر قدوم هذه الحملة أسماع الجيش الصليبي أصدرت قيادته العسكرية أوامرها بالإنسحاب، بعد ان وجدوا أنفسهم هذه المرة على عكس الهجمات السابقة، حيث كان الجيث الصليبي مضطراً هذه المرة لمواجهة الجيش المصري والثامي معاً، فمالوا إلى عقد الصلح مع الفاطميين، سيما عندما "رأى الفرنج ان البلاد - اي مصر - قد امتنعت عليهم وريما سلمت الى الملك نور الدين،

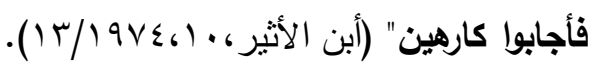
ولما أقتربت الحملة العسكرية الثالثة من القاهرة، أنسحب الصليبيون منها، ودخلها القائد شيركوه فاسُتقبل أستقبال المنتصرين، ولماعلمَ الملك نور الدين بهذا الخبر، سُرَّ به، وعدَه"فتحا جليدا لمصر، وحفظا لبلاد الشام وغيرها" (أبن الأثير ، ـ (

\section{رلايعاً: بسط النقوذ الزنكي على مصر : -}

بعد دخول أسد الدين شيركوه بقواته إلى القاهرة، رحبَ به الخليفة العاضد، وخلع عليه منصب الوزارة، ولقبه بالملك المنصور (أبن تغري بردي،بلات،ر/مبر) فعملَ على تنظيم شؤون الوزارة، وتثبيت النفوذ الزنكي في مصر، بعد ان تمكن من القضاء على معارضيه والسيطرَة على شؤون

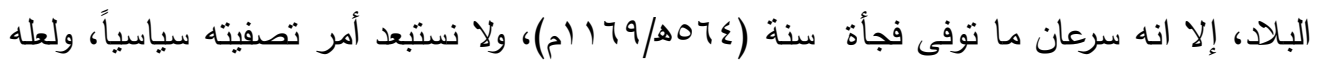
أغتيل على يد أحد الأشخاص المقربين إليه، وهذا أمر وارد في ظل الاجواء السياسية المضطربة التي

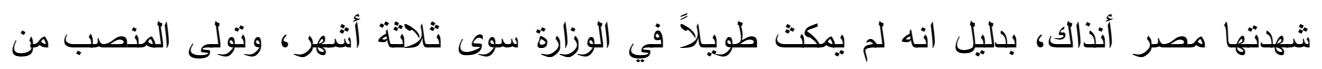

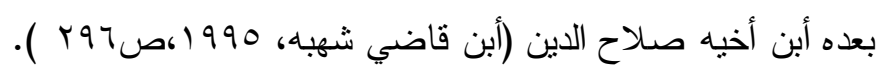
وبتولي صلاح الدين منصب الوزارة الفاطمية، ترسخ النفوذ الزنكي في مصر ، وأصبح أكثر قوة. لكننا نلاحظ ان آراء المؤرخين كانت مختلفة حول تولي صلاح الدين هذا منصب ، فأبن الاثير كان يرى ان مستشاري الخليفة العاضد هم الذين أشاروا عليه بتوزير صلاح الدين، فقال: "وكان الذي حمله- اي العاضد - على ذلك ان أصحابه قالوا له: ليس في الجماعة أضعف ولا

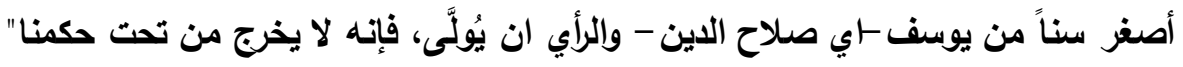

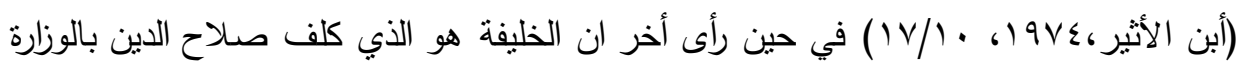

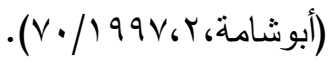


العدد الثاني والأربعون

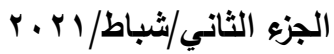

\section{جامسعة واسـط كليط}

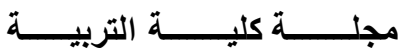

في قبال ذلك نرى ان نلك الأراء بعيدة عن الحقيقة، فكما بينا، فلم يكن الخليفة العاضد ولا امرائه

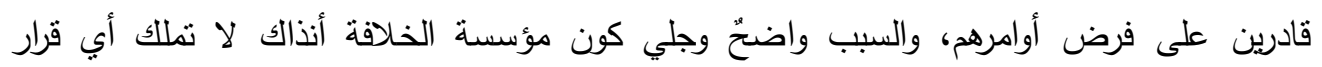

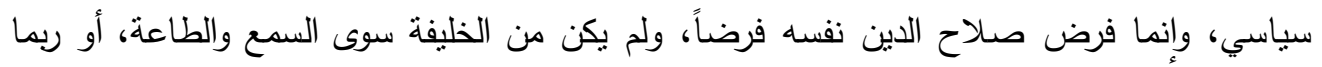

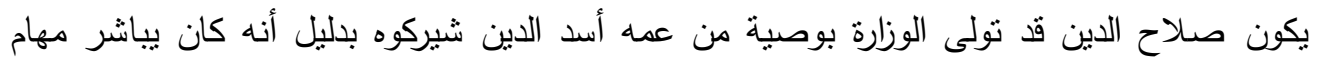

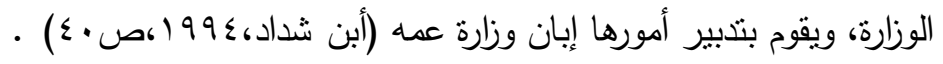

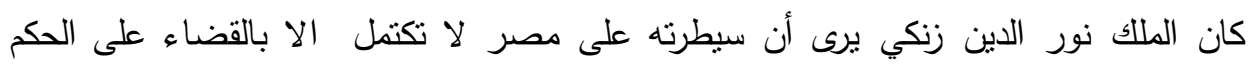

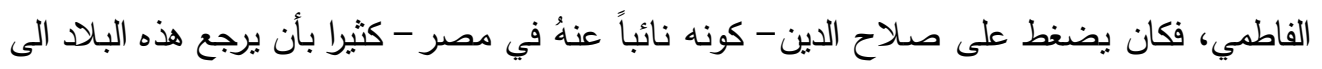

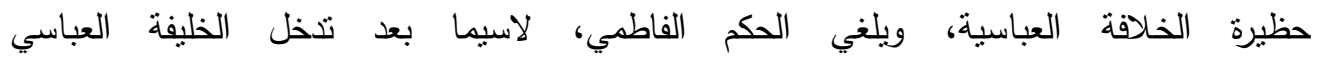

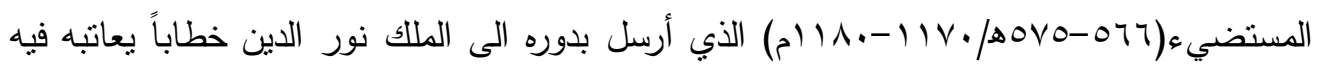

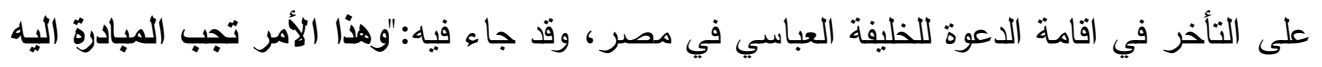

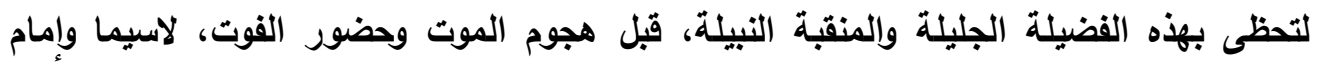

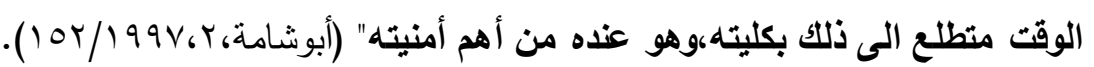

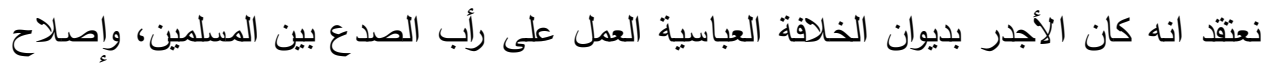
ذات بينهم، والتتسيق مع الخلافة الفاطية للتصدي للخطر الصليبي الداهم على الاراضي الإسلامية.

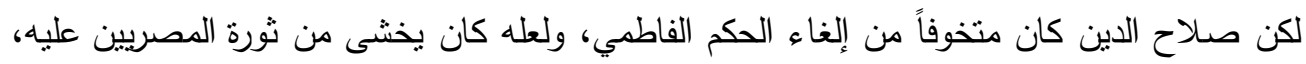

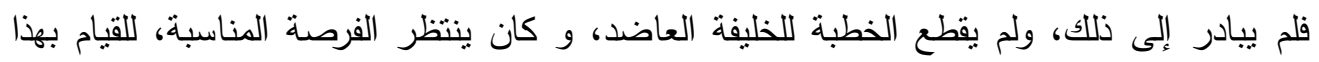

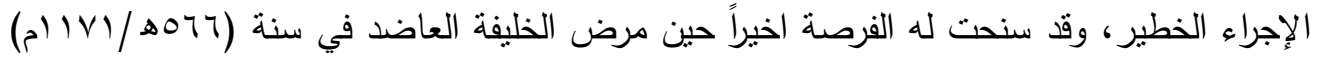

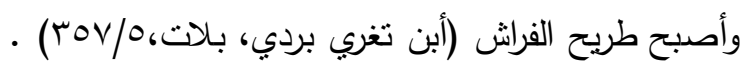
فضلاً عن ذلك، فقد نركَ الإحاح المستمر من قبل الملك نور الدين زنكي على صلى صلاح الدين أثرهُ

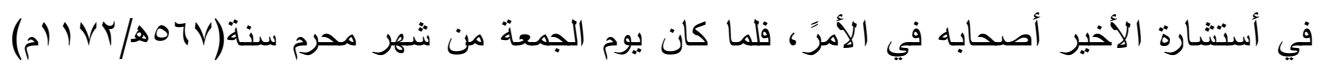

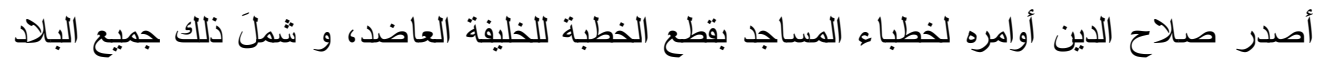
المصرية. بعدها نوفي الخليفة العاضد في قصره، وانقضى الحكم الفاطمي.وتم بذللك سيطرة الزنكيين

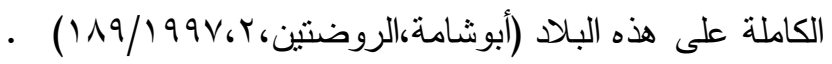


العدد الثاني والأربعون

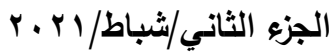

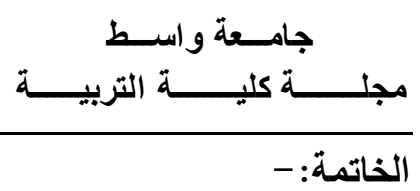

بحمد الله وتوفيقه، أنتهى بحثنا هذا الذي تطرقَ إلى موضوع (أثر الهجمات الصليبية في بسط النفوذ

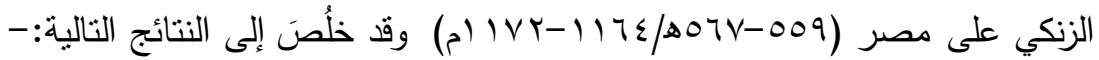
ا - كان الملك نور الدين زنكي يدرك تماماً أهمية موقع مصر الإستراتيجي، فضلاً عن نقلها السياسي والإقتصادي، لتمويل مملكته، وجيشه لمواجهة الصليبيين، فحرص على دخولها، وبسط نفوذه فيها . r- لم يكن الهذف من الحمات العسكرية الثلاث التي أرسلها الملك نور الدين زنكي الى مصر

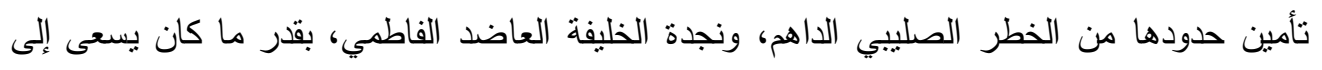
إقامة نفوذ جديد له، وتحقيق هدفه بضم مصر إلى مملكته في بلاد الثام • r- أراد الملك نور الدين بقضائه على الخلافة الفاطمية في مصر - المنافس السياسي، والديني الأقوى للخلافة العباسية أنذاك - كسب ود الخليفة العباسي، ومساندته في بسط النفوذ الزنكي على 
العدد الثاني والأربعون

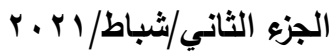

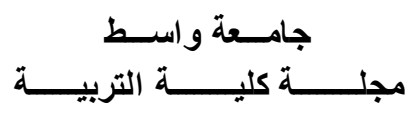

قائمة المصادر والمراجع :

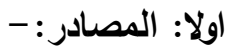

1-أبن الأثير، أبو الحسن علي محمد بن محمد الثيباني(ت . rا7ه/ ب ب ام). r -الكامل في التاريخ، تحقيق: عبداله القاضي،ط بـ، دار الكتب العلمية.

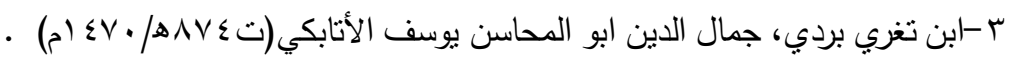

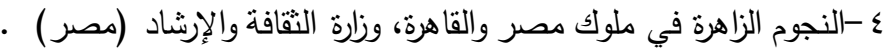

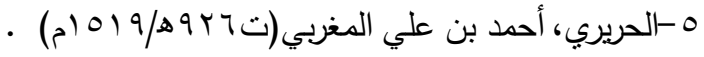

צ-الإعلام والتبيين في خروج الفرنج الملاعين على ديار المسلمين، تحقيق: سهيل زكار ، مكتبة دار الملاح.

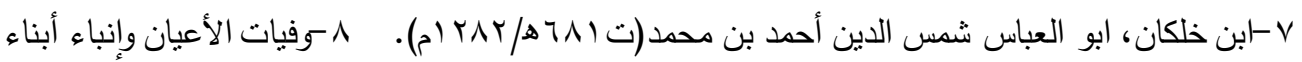
الزمان، تحقيق: إحسان عباس، دار الثقافة.

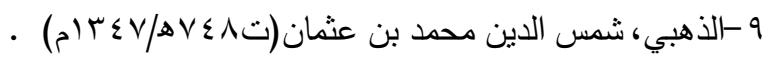
• 1 - تاريخ الاسلام ووفيات المشاهير والاعلام ، تحقيق: عمر عبد السلام تدمري، طا الدار الكتاب العربي .

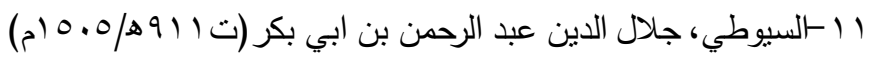

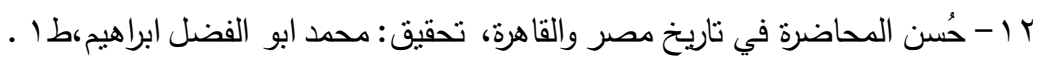

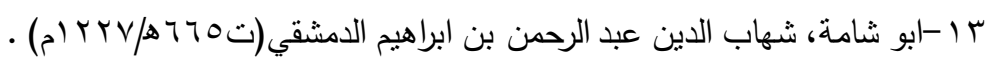
ـ ا -الروضتين في أخبار الدولتين النورية والصلاحية، تحقيق: إبراهيم الزيبق طا أ مؤسسة الرسالة(بيروت).

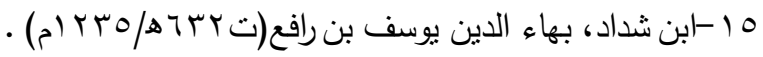
7 ا النوادر السلطانيةوالمحاسن اليوسفية(سيرة صلاح الدين)، تحقيق: جمال الدين الثيال، طب،مكتبة

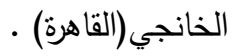

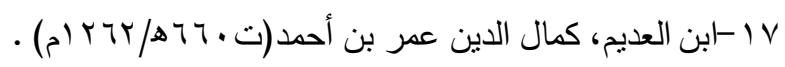
1 ا - زبدة الحلب في ناريخ حلب، تحقيق: سامي الدهان، المعهد الفرنسي، (دمشق).

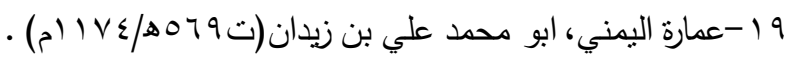
• r - النكت العصرية في أخبار الوزراء المصرية، تحقيق : هرتويغ درنبرغ، مطبعة مرسو ، (شالون) .

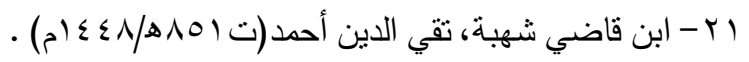

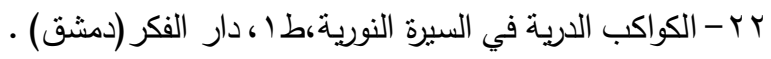

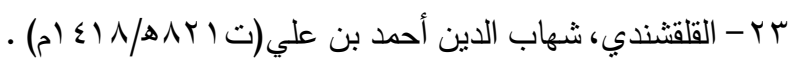

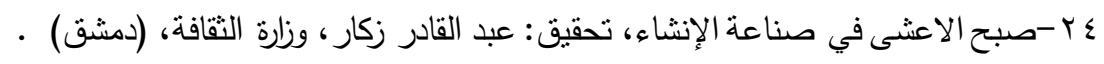

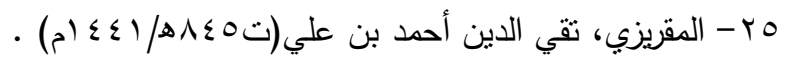
דr -السلوك لمعرفة دول الملوك، تحقيق: محمد عبد القادر عطا، ،ط ( كدار الكتب العلمية، (بيروت) .

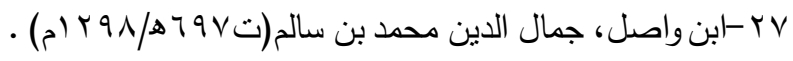


العدد الثاني والأريعون

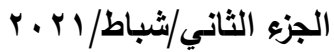

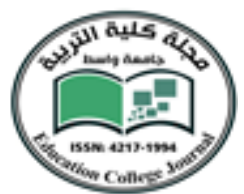

^ץ - مفرج الكروب في مناقب بني أيوب، تحقيق : جمال الدين الثيال، مطبعة باربس، (القاهرة) .

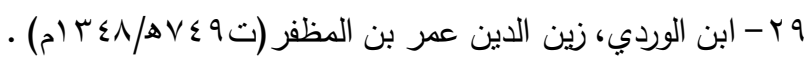
• r- التاريخ المعروف ب(تاريخ ابن الوردي)ط إ، دار الكتب العلمية، (بيروت).

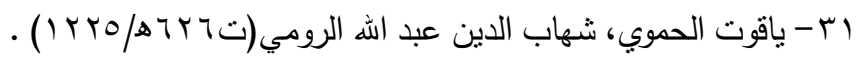

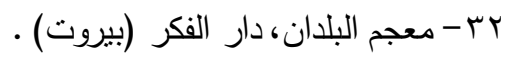

ثانياً: المراجع: مب-بيومي، علي

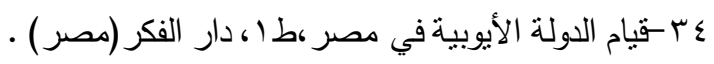

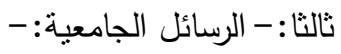

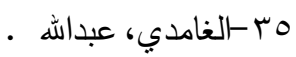

بr-استرداد بيت المقد في عصر صلاح الدين، رسالة ماجستير غير منشورة، جامعة ام القرى (مكة • المكرمة ) 